\title{
Smart City in the Building and Environmental Planning Program (RTBL) of the Ampenan Old Town
} Area

\author{
Siti Puspita Hida Sakti MZ dan Marzuki Adami \\ \{email: puspita_siti@yahoo.co.id; marzukiadami@gmail.com\} \\ Program Studi Sistem Informasi \\ STMIK Syaikh Zainuddin NW Anjani Lombok Timur NTB
}

\begin{abstract}
The City Government of Mataram established the Ampenan old town as a strategic trade and tourism service center using the Regional Spatial Plan (RTRW) in 2011 - 2031. Through the Building and Environmental Planning Program (RTBL) in 2013, the government made an architectural arrangement and approach to the Ampenan Old Town to develop the city to a more civilized level. The Regional Medium Term Development Plan (RPJMD) in 2016-2021 attempts to actrualize the concept of Smart City in the Mataram City Area, including the Ampenan old town. The study uses a qualitative method to compile the concept of Smart City in the Ampenan Old town based on Smart Living and implement the Building and Environmental Planning Plan (RTBL) strategy. It helps the Government to transform Ampenan Old town to a tourism center by introducing old buildings with cultural values, a unique culinary heritage, and festivals related to the diversity of each ethnic groupt. The techniques used in collecting data include interview, observation, study data and documentation. This study shows that the development of the smart city should be supported by qualified networks, such as $4 \mathrm{G}$, on mobile sim cards or access to the internet. Internet activities can be used as a basis for the development of smart cities oriented to nifty living with supporting infrastructure.
\end{abstract}

Keywords: smart city, smart living, Ampenan Old city, rtbl

\section{Pendahuluan}

Ampenan merupakan salah satu kecamatan di wilayah Kota Mataram. Kota tua Ampenan dahulunya adalah kota pelabuhan dan pusat perdagangan terbesar di Lombok. Pelabuhan kota tua Ampenan pembangunannya dimulai sekitar tahun 1924 pada masa penjajahan Belanda. Kemudian pada zaman kemerdekaan 1948-1950, pelabuhan kota tua Ampenan di kembangkan lagi dengan sejumlah renovasi. Saat itu, melalui pelabuhan Ampenan, barang maupun lalu lintas 
manusia keluar masuk dari dan ke Lombok berupa hasil bumi yaitu kerbau, sapi, tembakau, palawija serta berbagai hasil pertanian dan perkebunan.

Pada tahun 1970, pelabuhan Ampenan ditutup karena tidak strategis dan potensial untuk dikembangkan menjadi pelabuhan besar sehingga aktivitas pelabuhan dialihkan ke pelabuhan Lembar Kabupaten Lombok Barat yang berjarak $26 \mathrm{~km}$ dari kota Mataram dan pusat perdagangan kota tua Ampenan dipindahkan ke wilayah Cakranegara. Pasca perpindahan pelabuhan tersebut perekonomian di Ampenan merosot sehingga menjadi kawasan tua yang ditinggalkan. Pelabuhan lama Ampenan kini menjadi kawasan pariwisata baik wisata bahari ataupun wisata budaya namun masih belum maksimal.

Ampenan dalam bahasa Sasak berarti amben alias tempat singgah merupakan kawasan yang dikembangkan menjadi Pelabuhan oleh Belanda untuk menyaingi dominasi kerajaan-kerajaan di Bali. Belanda merancang kawasan ini terdiri dari pelabuhan, gudang-gudang barang, permukiman, areal pertokoan dan sarana pendukung lainnya. Ampenan sebagai kota pelabuhan pada umumnya dihuni oleh berbagai etnis seperti Tionghoa yang oleh Belanda dipekerjakan sebagai tenaga kerja murah, etnis arab, melayu dan bugis. Keragaman budaya ini ditemui di Jalan Yos Sudarso yang pada satu sisi berdiri ruko-ruko kuno milik warga Tionghoa dan sisi lainnya toko milik komunitas Arab yang menjual-barang-barang khas timur tengah. Seluruh bangunannya memiliki arsitektural kolonial dengan pola penataan grid yang dalam perkembangannya mulai pudar seiring perbangunan yang tidak terkendali. Hal ini disebabkan tidak adanya guidelines sebagai acuan dalam pengembangan kawasannya [1]. Kota tua Ampenan apabila memiliki tata kelola kota yang smart, hasil kebudayaan yang ada dilestarikan hingga kawasan perkotaan yang memiliki bangunan-bangunan lama dijaga dan dikembangkan sehingga memiliki harga jual, maka tidak menutup kemungkinan perekonomian masayarakat akan meningkat. Pemerintah kota mataram tidak melakukan penggusuran pada kawasan yang memiliki bangunan lama namun memberikan pemahaman kepada pemilik bangunan untuk membantu melestarikan kebudayaan sekaligus membuka peluang usaha di bidang pariwisata. Dengan menampilkan bangunan lama namun dikelola secara modern sehingga akan menghasilkan suasana vintage yang tentu dengan sejarah dibalik bangunan tersebut.

Pemerintah Kota Mataram melalui Rencana Tata Ruang Wilayah (RTRW) Kota Mataram Tahun 2011 - 2031 yang tercantum di dalam Perda No. 12 Tahun 2011 menetapkan kawasan kota tua Ampenan sebagai salah satu Pusat Pelayanan Kota (PPK) dalam pola inti berganda (multiple nuclei) dengan fungsi sebagai pusat perdagangan dan pelayanan pariwisata sekaligus merupakan kawasan strategis baik dari sudut kepentingan pertumbuhan, ekonomi maupun dari sudut kepentingan sosial-budaya.

Sejalan dengan program Pemerintah Kota Mataram dalam dokumen Rencana Tata Bangunan dan Lingkungan (RTBL) Kota Tua Ampenan Tahun 2013 yang disusun selama 8 bulan, kawasan Kota Tua Ampenan melalui penataan dan pendekatan arsitektural yang merupakan salah satu strategi pengembangan kota berbudaya di kota Mataram.

Masih menjadi bagian dari program Pemerintah Kota Mataram, salah satu Rancangan Pembangunan Angka Menengah Daerah (RPJMD) Kota Mataram tahun 2016-2021 adalah berupaya mewujudkan konsep smart city di Wilayah Pemerintahan Kota Mataram. Termasuk kawasan kota tua Ampenan dan sebagai bagian dari revitalisasi kawasan kota tua Ampenan

Smart city atau secara harfiah berarti kota pintar, merupakan suatu konsep pengembangan, penerapan, dan implementasi teknologi yang diterapkan disuatu daerah sebagai sebuah interaksi yang kompleks di antara berbagai sistem yang ada di dalamnya [2]. Tujuan dari pendekatan smart city untuk mencapai informasi dan pengelolaan kota yang terintegrasi. Integrasi ini dapat melalui manajemen jaringan digital geografi perkotaan, sumber daya, lingkungan, ekonomi, sosial dan lainnya. 
IBM merupakan perusahaan yang mewadahi berdirinya smart city, IBM membagi smart city menjadi enam jenis. Keenam jenis pembagian smart city tersebut meliputi smart economy, smart mobility, smart governance, smart people, smart living, dan smart environmen [2].

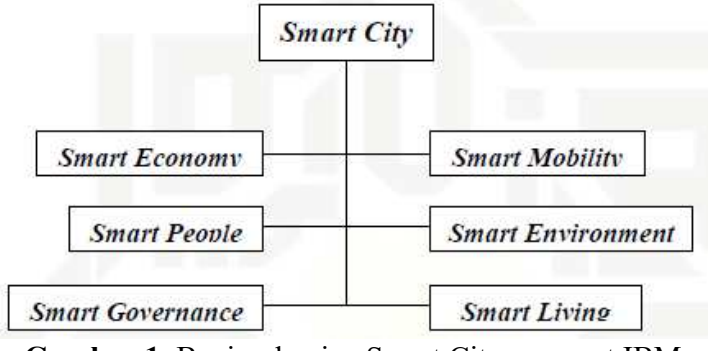

Gambar 1. Bagian-bagian Smart City menurut IBM

Smart living mengacu pada kualitas hidup dan kebudayaan masyarakat. Faktor yang paling mempengaruhi adalah tersedianya kebutuhan-kebutuhan, keamanan, keselamatan, kemudahan dan kenyamanan hidup. Menurut [3], sebuah kota ditetapkan sebagai smart city jika menyeimbangkan pembangunan ekonomi, sosial, dan lingkungan, dan jika terhubung dengan proses demokrasi melalui pemerintah partisipatif.

\section{Metode}

Metode yang digunakan dalam penelitian ini adalah metode kualitatif. Metode ini digunakan untuk menyusun konsep pengimplementasian smart city Kota Tua Ampenan dalam Rencana Tata Bangunan dan Lingkungan (RTBL) berbasis smart living. Adapun teknik pengumpulan data yang digunakan adalah dengan menggunakan teknik wawancara, observasi, data studi dan dokumentasi.

\section{Hasil dan Pembahasan}

\subsection{Konsep Smart City di Kota Mataram}

Visi Kota Mataram tahun 2016-2021 adalah terwujudnya kota Mataram yang maju, religius dan berbudaya. Secara visual salah satunya dimplementasikan pada kota tua Ampenan.Salah satu Rancangan Pembangunan Angka Menengah Daerah (RPJMD) Kota Mataram tahun 20162021 adalah berupaya mewujudkan konsep smart city di Wilayah Pemerintahan Kota Mataram. Pemerintah kota telah bersepakat dengan PT Tower Bersama Group (TBG) untuk menyiapkan infrastruktur yang mendukung konsep smart city yakni menempatkan tiang antena di sejumlah titik (25 titik) dengan beberapa pertimbangan.

- Menempatkan sisi estetika dalam mendirikan tiang antena seperti tidak merusak keindahan lokasi penempatan tiang antena

- Dihias layaknya pohon sintetis yang menyatu dengan pohon sekitar

- Mengumandangkan suara adzan saat waktu shalat tiba

- Penempatan CCTV pada tiang antena bertujuan untuk memantau secara real time terkait suatu kondisi suatu wilayah Pemerintah Kota mataram. 
Pemamfaatan aplikasi smart city dan call center di kota Mataram belum massif, fasilitas panggilan penting dan darurat dari kedua aplikasi ini harus disosialisasikan kepada masyarakat. Padahal kedua aplikasi ini dapat membantuk kemunikasi dan informasi kepada masyarakat tentang kondisi cuaca ekstrem khususnya dalam beberapa pekan terakhir ini. Hal ini dikarenakan alat pendukung yang ada belum maksimal, hanya dapat diakses secara terbatas pada organisasi perangkat daerah (OPD).

Aplikasi smart city Kota Mataram telah diluncurkan bersamaan dengan Program Layanan Aspirasi dan Pengaduan Online Rakyat atau LAPOR pada 31 Agustus 2017 bertepatan dengan HUT Kota Mataram. Pemerintah Kota Mataram memberikan fasilitas android bagi para pimpinan OPD termasuk camat dan lurah di lingkup Kota Mataram secara bertahap hingga anggaran tahun 2018. Para pimpinan OPD harus mampu mengoperasikan aplikasi smart city ini pada androidnya masing-masing dan segera menyiapkan langkah-langkah penanganan dari laporan tersebut.

Aplikasi "Mataramku LAPOR" ini dapat di pasang pada ponsel milik masyarakat agar dapat melaporkan secara langsung terkait permasalahan yang ada di seputar wilayah Kota Mataram. Begitu diunggah melalui aplikasi tersebut, laporan dapat langsung ditanggapi oleh OPD terkait sehingga penanganan menjadi lebih cepat. Layanan lain dari Mataram berkonsep smart city ini seperti pemasangan CCTV di beberapa titik untuk pengawasan sampah di TPA dan lalu lintas command center. Pemerintah kota Mataram juga berencana menyiapkan koneksi internet bagi masyarakat dan beberapa layanan lainnya yang kesemuanya ini dipantau oleh Walikota dan Wakil Walikota Mataram melalui ponsel juga.

Layanan lain yang dapat diintegrasikan dengan Mataram smart city adalah smart living terkait dengan kota tua Ampenan.

\subsection{Konsep smart city dalam strategi pengembangan tata kelola kota berbudaya pada kawasan Kota Ttua Ampenan}

Wilayah perkotaan dibagi menjadi beberapa kawasan sehingga penyelesaian masalah perkotaan bisa lebih fokus dan sesuai sasaran serta sejalan dengan visi dan misi Pemerintahan Kota, misalnya kawasan perekonomian, maka untuk meningkatkan perekonomian rakyat, hilangnya pasar rakyat digantikan dengan gedung-gedung tinggi sebagai pusat perbelanjaan seperti mall-mall dan pertokoan-pertokoan. Biasanya kawasan perekonomian tidak jauh dari tempat-tempat makan dan dijadikan sebagai bagian dari wisata kuliner dengan bermunculannya restoran-restoran dan cafe-cafe yang tentu menarik kaum muda untuk sekedar hangout bersama teman-temannya. Dulunya sebelum menjadi kawasan mall dan pertokoan, perekonomian masyarakat ditopang dengan adanya pasar rakyat yang ramai. Selain menjual hasil pertanian maupun peralatan pertanian seperti sabit dan cangkul terkadang pasar rakyat juga menampilkan kebudayaan yang menjadi bagian sebuah masyarakat namun budaya ini tidak akan kita temui di mall-mall atau kawasan pertokoan. Tempat-tempat makan sedehana seperti warung dan kedai tergantikan dengan restoran dan café, padahal kalau kita melihat ke belakang kawasan perekonomian ini merupakan bagian dari sejarah dan kebudayaan yang harus dilestarikan maka akan sangat sayang apabila bangunan-bangunan tua yang sudah ada dikawasan ini sejak dulu di robohkan dan digantikan dengan gedung-gedung baru yang modern. Selain itu, warung dan kedai kecil yang menampilkan kesan sahaja harusnya dapat dikembangkan dan memiliki manajemen ekonomi sehingga dapat meningkatkan hasil penjualan. Misalnya memberikan bantuan untuk mempercantik bangunan-bangunan tua tanpa merubah struktur bangunan dan meningkatkan pelayanan pada kawasan wisata kuliner yang tentu saja menampilkan kesahajaan dan kesederhanaan sebagai bagian dari sebuah kebudayaan. Bukan berarti kawasan ini tidak dibangun kembali namun beberapa bangunan tua yang memiliki nilai sejarah dilestarikan dan 
digunakan seperti sebelumnya namun perlu diperbaiki sehingga dapat memunculkan kesan vintage dan sederhana.

Pengunjung juga dapat belajar dari sejarah misalnya kuliner nasi puyung yang sangat terkenal padahal penampilannya sederhana. Hal ini dapat dikembangkan dan tentu tidak menjadi sebuah ketimpangan apabila disebelahnya terdapat bangunan baru yang bertingkat bahkan jalanjalan yang sederhana menimbulkan kesan melankonis dan vintage. Hal ini menjadi nilai jual pariwisata karena besarnya pengaruh hasil photo selfie dan dapat membuat sesuatu menjadi terkenal dalam hitungan detik.

Upaya Pemerintah Kota Mataram dalam rangka revitalisasi kota tua Ampenan pada skala terbatas adalah penataan fisik namun cakupan revitalisasi kawasan menyangkut aspek-aspek ekonomi, sosial, budaya dan fisik. Oleh karena, program revitalisasi ini harus mempertegas aspek legalitas dibawah pengawasan aparat terkait dan keikutsertaan masyarakat pengguna/sekitar kawasan kota tua Ampenan.

Dalam konteks pelestarian, revitalisasi dilakukan dengan 4 motif yaitu :

- Melindungi kawasan budaya/bersejarah "urban artifact"

- Menjamin variasi dalam bangunan perkotaan sebagai tuntutan aspek estetis dan variasi budaya masyarakat

- Bidang ekonomi, menganggap bangunan yang dilestarikan dapat meningkatkan nilai komersial dan digunakan sebagai modal lingkungan

- Simbol, menganggap bentuk fisik merupakan identitas dari suatu kelompok masyarakat tertentu yang pernah menjadi bagian dari suatu kota

Program yang direncanakan Pemerintah Kota Mataram untuk penataan kota tua Ampenan khususnya eks Pelabuhan Ampenan adalah membangun ruang public yang dilengkapi dengan berbagai aktivitas bermain, olahraga dan edukasi seperti halnya pada penataan ruang terbuka hijau (RTH) lainnya dikota Mataram serta mendukung program smart city dalam mengembangkan dan mengenalkan kota tua Ampenan sebagai salah satu budaya di wilayah Kota Mataram. Pada kegiatan TAKSA, 2013 yang diadakan Jaringan Pusaka Indonesia difokuskan pada kota tua Ampenan yang terpilih sebagai lokus pembelajaran langsung baik sebagai issue konvensional dalam pelestarian maupun melihat sebagai sebuah wahana pembelajaran bagaimana mensinergikannya dengan pengelolaan bangunan tua dan lingkungan kota tua Ampenan. Misalnya pada bagian hilir Sungai Jangkok.

Salah satu kegiatan yang dapat dilakukan di Kota Tua Ampenan dan merupakan dukungan konsep smart city pada wilayah Kota Mataram antara lain :

- Jelajah kota pusaka Ampenan dan Kelenteng Pao Hwa Kong J1. Yos Sudarso 180 Ampenan

- Peluncuran Program eco Climate Village (KKP) dan PNPM Pusaka Kepulauan (Kemenko Kesra)

Pengembangan dan pembuatan perangkat lunak (software) Rencana Tata Bangunan dan Lingkungan (RTBL) sebagai implementasi Rencana Tata Ruang Wilayah (RTRW) Kota Mataram tahun 2011-2031 yang mencakup areal sungai Jangkok, jalan Pabean, perlimaan Ampenan dan eks pelabuhan Ampenan menggunakan APBD sedangkan Jaringan Pusaka Indonesia mengintervensi pelestarian bangunan tua Ampenan dan payung hukumnya.

Pusaka atau heritage adalah warisan yang memiliki nilai penting pada masa lampau, hingga kekinian dan masa depan yang menjemputnya. Pusaka alam dan pusaka budaya yang meninggalkan jejak sejarah perlu dilestarikan dan sebagai dukungan pada pengembangan kota serta dapat menjadi bagian dari implementasi konsep smart city. Masyarakat dan daerah kawasan kota tua Ampenan sebagai pemilik pusaka, pemuda sebagai pewaris dan pengampu pusaka, dan perubahan iklim dan beberapa dekade terakhir sebagai pertimbangan yang mempengaruhi keberadaan pusaka [5]. 
Rencana Tata Ruang Wilayah (RTRW) Kota Mataram Tahun 2011-2031 sebagai dukungan terhadap pengembangan dan pengimplementasian konsep Smart City antara lain:

1. Pusat Pelayanan Kota (PPK), Pengembangan Pusat Pelayanan Ampenan berbasis smart city

2. Pusat Lingkungan (PL) yang dipisahkan berdasarkan kawasan misalkan kawasan perdagangan seperti pasar, kawasan wisata seperti pantai, bangunan tua dan waterpark, serta kawasan lainnya yang masing-masing memiliki fokus terkait,

3. Rincian Pengembangan rute penyebrangan wisata pantai yang melewati pantai Ampenan. Rute ini akan ditambahkan pada layanan informasi kota tua Ampenan

4. Rencana pengembangan sistem jaringan energi dan ketenagalistrikan. Layanan memberikan informasi lokasi Pembangkit dan bila terjadi kebocoran, maka sirene akan berbunyi sebagai info kepada masyarakat untuk melakukan evakuasi dan menjauh dari area kebocoran

5. Pengembangan Sistem Jaringan Jalan, Pembangunan Jalan

6. Kawasan cagar budaya dan pengembangan kawasan Kota Tepian Air (Waterfront Air). Layanan memberikan informasi tetang lokasi dan informasi lain yang terkait

7. Revitalisasi Kawasan Kota Tua Ampenan. Terkait dengan berbagai fokus masing-masing kawasan dan penerapan konsep smart city dalam pelaksanaan revitalisasi

8. Pengembangan kawasan perdagangan dan jasa skala regional dan lokal, Pengembangan dan revitalisasi kawasan pusat perbelanjaan dan niaga

9. Pengembangan kawasan peruntukan pendidikan, pengembangan fasilitas sekolah dan bagian kesehatan. Misalnya antar UGD pada fasilitas kesehatan.

\subsection{Konsep smart living dalam mendukung impelementasi Rencana Tata Bangunan dan Lingkungan (RTBL) Kawasan Kota Tua Ampenan}

Konsep smart city khususnya smart living di kawasan kota tua Ampenan salah satunya bertujuan untuk memperkenalkan bangunan-bangunan yang memiliki nilai budaya dan kuliner khas yang diteruskan dari masa lalu dapat memberikan kontribusi secara ilmiah. Harga yang ditawarkan baik wisata budaya, bangunan maupun kuliner khasnya memiliki kualitas yang sepadan. Informasi-informasi masing-masing kawasan yang ada di kota tua Ampenan dapat diberikan dalam bentuk layanan smart city, sehingga bila ada pengunjung yang ingin mendatangi kota tua Ampenan, mereka dapat memperoleh informasi sejarah dari bangunanbangunan. Kemudian pada sore harinya mereka dapat menikmati senja di café-café diantara bangunan-bangunan tua. Sehingga mereka dapat merasakan suasana atau dapat membayangkan suasana pelabuhan dan kota Ampenan pada zaman dulu. Bila cuaca mendukung mereka dapat melihat keeksotisan pantai Ampenan saat senja dan merasakan angin malam dalam suasana beberapa ruas jalan dikawasan kota tua Ampenan ini.

Pada smart living, menurut [2] terdapat syarat dan kriteria serta tujuan untuk proses pengelolaan kualitas hidup dan budaya yang lebih baik dan pintar. Untuk mewujudkan smart living terdapat tiga buah sub bagian yang harus dipenuhi, diantaranya sebagai berikut:

1. Fasilitas-fasilitas pendidikan, yang memadai bagi masyarakat dengan memamfaatkan teknologi informasi seperti penyediaan sarana internet gratis dan sehat (bebas dari konten pornografi, kekerasan, melalui sistem filtering/proxy, CCTV yang terpasang ditempat umum dan lalu lintas untuk menekan jumlah kriminal

Penelitian-penelitian bangunan bersejarah sebagai bagian dari pendidikan baik oleh siswa, mahasiswa dan peneliti dapat melakukan penelitian di kawasan kota tua Ampenan dan dengan adanya layanan berbasis smart city maka mereka mendapatkan informasi awal maupun tambahan selain mengunjungi langsung bangunan tuanya.

Baik di Pelabuhan maupun kota Ampenan, warga maupun pengunjung memiliki akses wifi yang disiapkan pemerintah atau jaringan kartu-kartu ponsel yang memiliki jaringan $4 \mathrm{G}$ sehingga 
dapat digunakan untuk mencari informasi atau kegiatan lainnya yang sehat sambil menikmati kawasan kota tua Ampenan.

Sumber daya manusia (SDM) yang dibutuhkan menuju smart city dan kota budaya perlu diadakan dan ditingkatkan. Perpindahan kegiatan yang awalnya manual ke arah Teknologi Informasi dan Komunikas (TIK) diperlukan kemampuan yang mumpuni. Kegiatan yang dilakukan untuk membantu penerapan smart city dari sisi SDM adalah perlu adanya pelatihan cara penggunaan layanan yang berbasis komputer dan mobile serta dan pencarian informasi tetang budaya misalnya acara di suatu bangunan tua yang menampilkan cerita rakyat, kesenian khas atau acara-acara yang merupakan bagian dari tradisi di masyarakat yang tentunya informasi kegiatan tersebut sekali lagi diberikan melalui layanan internet mapun jejaring sosial dalam hal ini berkonsep smart city karena dalam satu layanan, masyarakat dapat memberikan informasi dan menerima informasi akan suatu acara atau festival dengan waktu, tempat dan aksesoris serta persyaratan mengikuti acara lainnya.

Data yang dibutuhkan untuk layanan berbasis smart city di pada kawasan tua Ampenan berupa data bangunan lama dan bersejarah dari kantor arsip serta informasi terkait bangunan. Selain itu, informasi tentang posisi dan kekuatan bangunan tua yang ada di kawasan kota tua Ampenan dari Badan Pertanahan Nasional (BPN). Berdasarkan data yang ada ini maka Pemeritah Kota dapat memberikan layanan lebih atau menambahkan layanan sehingga informasi yang diberikan semakin akurat dan dapat dimengerti oleh masyarakat.

2. Penyediaan sarana, prasarana dan informasi terkait dengan potensi pariwisata daerah dengan baik dan aktraktif memamfaatkan teknologi informasi seperti adanya sistem informasi geografis untuk pemetaan lokasi objek wisata, proses pemesanan tiket masuk objek wisata dan kamar hotel secara online dan mobile.

Dalam rangka revitalisasi kawasan kota tua Ampenan diperlukan juga tata kelola kawasan dan rancangan budaya yang akan ditampilkan kawasan kota tua Ampenan, salah satunya kegiatan-kegiatan keagamaan dari masing-masing etnis atau masyarakat yang ditampilkan dalam bentuk Festival sehingga mendatangkan wisatawan bail luar maupun dalam negeri. Informasi-informasi tentang festival maupun kegiatan kebudayaan yang diadakan di kota tua Ampenan dapat ditampilkan dalam sebuah website atau informasi layanan entah melalui layanan sms ataupun jejaring sosial

3. Infrastruktur teknologi informasi yang memadai, sehingga semua fasilitas dan layanan public dapat berjalan dengan baik melali bantuan komputerisasi dan teknologi informasi seperti tersedianya komputer publik ditempat-tempat umum, tersedianya jaringan internet yang memadai, tersedianya tenaga IT/SDM yang kompeten.

Setelah mengetahui rancangan pengembangan kota dari Pemkot dalam hal ini tata kelola dan tata ruang yang waktu realisasinya diberikan jangka waktu beberapa tahun, maka pengerjaannya dilakukan melalui tender/proyek atau dikerjakan sendiri oleh dinas terkait atau gabungan beberapa dinas menggunakan APBD dan pagu dana lainnya. Agar rancangan kota yang telah diatur oleh Pemkot maupun Kecamatan Ampenan sendiri harus sejalan dengan dukungan masyarakat. Konsep smart city yang dimplementasi dalam pembangunan kota Mataram khususnya kota tua Ampenan harus memasukkan pemikiran masyarakat terkait sehingga konsep smart city dapat mengimplementasikan informasi sejarah dan budaya yang ada dan lahir di kota tua Ampenan. Pembangunan smart city membutuhkan banyak hal salah satunya infrstruktur dan dana yang mendukung dalam hal pembangunan infrastruktur baru yang diperlukan atau perbaikan dan pemugaran bangunan-bangunan tua atau pengembangan kawasan kota tua yang menerapkan smart city dalam hal wisata bangunan dan kuliner sert meningkatkan perekonomian dan layanan ynag diberikan Pemrintah Kota Mataram pada kawasan kota tua 
Ampenan, contohnya revitalisasi kawasan kota dan pengadaan infrastruktur untuk mendukung dan mengimplementasikan kota tua Ampenan.

Penerapan smart city yang merupakan bagian dari perkembangan TIK membutuhkan yang namanya koneksi internet guna mengakses layanan atau website mengenai kota tua Ampenan. Jaringan internet ini pastinya harus didukung oleh infrastruktur jaringan seperti kartu ponsel yang memiliki jaringan $4 \mathrm{G}$ atau area-area gratis wifi yang disediakan di beberapa titik di kawasan kota tua Ampenan.

\section{Kesimpulan}

Penelitian ini dilakukan sebagai bagian dari usulan dalam mendukung rencana revitalisasi kota tua Ampenan dan sejalan dengan Rencana Tata Ruang Wilayah (RTRW) Kota Mataram Tahun 2011 - 2031 menetapkan kawasan kota tua Ampenan sebagai pusat perdagangan dan pelayanan pariwisata sekaligus merupakan kawasan strategis baik dari sudut kepentingan pertumbuhan, ekonomi maupun sosial-budaya.

Dalam dokumen Rencana Tata Bangunan dan Lingkungan (RTBL) Kota Tua Ampenan Tahun 2013, penataan dan pendekatan arsitektural kawasan Kota Tua Ampenan merupakan salah satu strategi pengembangan kota berbudaya di kota Mataram. Pengembangan dan pembuatan perangkat lunak (software) Rencana Tata Bangunan dan Lingkungan (RTBL) sebagai implementasi Rencana Tata Ruang Wilayah (RTRW) kota Mataram tahun 2011-2031

Salah satu Rancangan Pembangunan Angka Menengah Daerah (RPJMD) Kota Mataram tahun 2016-2021 adalah berupaya mewujudkan konsep smart city di Wilayah Pemerintahan Kota Mataram. Konsep smart city khususnya smart living di kawasan kota tua Ampenan salah satunya bertujuan untuk memperkenalkan bangunan-bangunan yang memiliki nilai budaya dan kuliner khas yang diteruskan dari masa lalu dengan tidak mengubah nilai namun cara pengenalannya disesuaikan dengan pekembangan zaman.

Pengembangan smart city ini harusnya didukung oleh jaringan mumpuni misalnya jaringan sim card ponsel yang telah mencapai $4 \mathrm{G}$ atau mampu mengakses internet. Beberapa kegiatan berinternet ini dapat dijadikan sebagai dasar pembangunan smart city berorientasi pada smart living dan tentunya masih perlu pembangunan infrastruktur pendukung lainnya.

\section{References}

[1] R. Deskarina, "Palce Branding Kawasa Kota Tua Ampenan, Lombok Berdasarkan persepsi dan ekspektasi stakeholders, Tesis," Universitas Gadjah Mada M, 2013.

[2] I. P. A. E. Pratama, Smart City Beserta Cloud Computing dan Teknologi-Teknologi Pendukung lainnya. Bandung: Informatika Bandung, 2014.

[3] A. Caragliu, C. del Bo, and P. Nijkamp, "Smart cities in Europe," J. Urban Technol., vol. 18, no. 2, pp. 65-82, 2011.

[4] TAKSA, Pusaka untuk Kesejahteraan Rakyat, Temu Pusaka Indonesia (TAKSA) 2013,Santiri Foundation, Lombok 12-15 September 2013. 2013.

[5] M. P. Kurniawan and A. Santosa, "Perancangan furnitur berbahan olahan rotan berbasis smart living untuk apartemen SOHO,” Intra, vol. 4, no. 2, pp. 87-100, 2016.

[6] Anonim, Perda Kota Mataram Nomor 12 Tahun 2011 tentang Rencana Tata Ruang Wilayah (RTRW) Kota Mataram Tahun 2011-203. 
[7] Anonim, 2013, RTBL Kawasan Kota Tua Ampenan, Kota Mataram Provinsi Nusa Tenggara Barat, Kementerian Pekerjaan Umum, Direktorat Jenderal Cipta Karya, Direktorat Penataan Bangunan dan Lingkungan.

[8] Anonim, Rencana Pembangunan Jangka Menengah Daerah (RPJMD) Kota Mataram tahun 20162021, Bapedda Kota Mataram 